\title{
Avaliação do desempenho mecânico e físico de argamassas com resíduo de cerâmica vermelha
}

\author{
Evaluation of the mechanical and physical performance of mortars \\ with red ceramic residue
}

\section{Evaluación del comportamiento mecánico y físico de morteros con residuo cerámico rojo}

Recebido em 29/10/2020 Aceito em 22/06/2021

PINZ, Francielli Priebbernow ${ }^{1}$

PALIGA, Charlei Marcelo ${ }^{2}$

TORRES, Ariela Da Silva

1 Programa de pós-graduação em Arquitetura e Urbanismo, Faculdade de Arquitetura, Universidade Federal de Pelotas. Pelotas, Rio Grande do Sul, Brasil franciellippinz@gmail.com ORCID: 0000-0003-2558-8683

2 Departamento de Tecnologia da Construção, Faculdade de Arquitetura e Urbanismo, Universidade Federal de Pelotas. Pelotas, RS, Brasil. charleipaliga@gmail.com ORCID: 0000-0003-0521-4764

3 Departamento de Tecnologia da Construção e Programa de Pós Graduação em Arquitetura e Urbanismo,Faculdade de Arquitetura e Urbanismo, Universidade Federal de Pelotas. Pelotas, RS, Brasil. arielatorres@gmail.com ORCID: 0000-0003-4686-9759 


\title{
Resumo
}

A busca por uma cadeia produtiva mais sustentável na indústria da construção civil está diretamente relacionada com a incorporação de materiais recicláveis em seus produtos, o que demanda uma extensa quantidade de estudos e avaliações sobre suas propriedades e seus efeitos. Considerando isto, este trabalho teve como objetivo avaliar o resíduo de cerâmica vermelha (RCV), proveniente da fabricação de tijolos de vedação, como substituinte parcial ao agregado miúdo ou ao aglomerante em argamassas. A aplicação foi avaliada em argamassas de cimento e areia quanto ao desempenho físico, através de ensaios de absorção por capilaridade, absorção por imersão e índice de vazios, e mecânico, por ensaios de compressão axial e tração na flexão. Os traços foram 1:3 e 1:6, com teores de $5 \%$ e $10 \%$ de substituição parcial ao aglomerante, e 10\%, 15\% e $20 \%$ ao agregado. As tipologias de argamassas mais afetadas foram na substituição ao agregado em comparação com a substituição no aglomerante, dada a porosidade do RCV. Já as substituições no aglomerante fizeram com que as mesmas tivessem um comportamento mais próximo dos traços de referência, mesmo nos teores de $10 \%$.

Palavras-Chave: argamassas, sustentabilidade, resíduo de cerâmica vermelha, tecnologia da arquitetura

\begin{abstract}
The search for a more sustainable productive chain, in the civil construction industry, is directly related to the incorporation of recyclable materials in its products, which demands an extensive amount of studies and evaluations on their properties and their effects. Considering this, this work aimed to evaluate the red ceramic residue (RCV), from the manufacture of sealing bricks, as a partial substitute for fine aggregate or agglomerate in mortars. The application was evaluated in cement and sand mortars for physical performance, through capillary absorption tests, immersion absorption and voids index, and mechanical, by axial compression tests and flexural tensile tests. The traces were 1: 3 and 1: 6 , with contents of $5 \%$ and $10 \%$ of partial substitution to the binder, and $10 \%, 15 \%$, and $20 \%$ to the aggregate. In both types of mortar, they were more affected when replacing in the aggregate compared to replacing in the binder, given the porosity of the RCV. The substitutions in the binder made them behave closer to the reference traits, even at 10\% levels.
\end{abstract}

Key-Words: mortars, sustainability, red ceramic residue, technology of architecture

\section{Resumen}

La búsqueda de una cadena productiva más sustentable, en la industria de la construcción civil, está directamente relacionada con la incorporación de materiales reciclables en sus productos, lo que demanda una extensa cantidad de estudios y evaluaciones sobre sus propiedades y sus efectos. Teniendo esto en cuenta, este trabajo tuvo como objetivo evaluar el residuo cerámico rojo (RCV), procedente de la fabricación de ladrillos de sellado, como sustituto parcial del agregado fino o aglomerado en morteros. La aplicación fue evaluada en morteros de cemento y arena en cuanto a desempeño físico, mediante ensayos de absorción capilar, absorción por inmersión e índice de vacíos, y mecánico, mediante ensayos de compresión axial y ensayos de tracción por flexión. Las trazas fueron 1: 3 y 1: 6, con contenidos de 5\% y 10\% de sustitución parcial al ligante, y 10\%, 15\% y $20 \%$ al agregado. En ambos tipos de mortero, se vieron más afectados al reponer en el agregado que en el recambio en el aglutinante, dada la porosidad del RCV. Las sustituciones en el aglutinante hicieron que se comportaran más cerca de los rasgos de referencia, incluso a niveles del $10 \%$.

Palabras Clave: morteros, sostenibilidad, residuo cerámico rojo, tecnología de la arquitectura 


\section{Introdução}

A construção civil possui uma cadeia produtiva que demanda a intensiva extração de recursos naturais e gera uma grande quantidade de resíduos, colaborando significativamente para a degradação ambiental. Para se adequar as atuais necessidades sociais, que demandam produções mais sustentáveis, é fundamental a busca por alternativas tanto de produção mais racionalizada com menor geração de resíduos, como de reciclagem dos resíduos gerados pela indústria da construção civil nos materiais construtivos.

A indústria da cerâmica vermelha, ou cerâmica estrutural, responsável por produzir blocos e tijolos cerâmicos, tem sua existência diretamente relacionada com a construção civil, e é de notável importância para a economia do país, apresentando um faturamento anual de aproximadamente $\mathrm{R} \$ 18$ bilhões (Dado coletado do ANICER). No entanto, sua cadeia produtiva com a extração da argila como matéria prima utilizada, e o processo de queima das peças, é altamente nocivo. Além disso, as falhas no processo produtivo das peças de cerâmica vermelha acabam por gerar o resíduo de cerâmica vermelha $(\mathrm{RCV})$. A quantidade deste resíduo varia de acordo com o nível tecnológico da fábrica, e, como no Brasil esta produção ainda é bastante artesanal, os índices giram em torno de $5 \%$ a $20 \%$ da produção (ABDI, 2016).

No entanto, além do agressivo impacto ambiental causado pela construção civil, esta indústria tem por característica também a grande importância econômica e social para o país e uma vasta possibilidade de incorporação e reciclagem de resíduos, tanto próprios como de outros setores. A elaboração de materiais construtivos com utilização de resíduos como adição ou substituição a outros materiais já se provou uma alternativa possível em vários estudos (OLIVEIRA et al., 2019; SAMANDI et al., 2015; SCHACKOW et al., 2015; QADIR, 2015; MEDEIROS et al., 2016; CASTRO et al., 2017; MORAIS et al., 2020), propiciando materiais de qualidade, redução de custo e principalmente uma produção mais limpa.

No caso do RCV, suas características possibilitam diversas aplicações. Por ser um material proveniente da argila e submetido a altas temperaturas, os resíduos de cerâmica podem possuir atividade pozolânica. Esta característica faz com que umas das possíveis reciclagens do RCV seja como pozolana, adição mineral ou clínquer na produção de cimentos. Sendo o cimento um dos materiais mais consumidos no mundo, e o seu processo de fabricação um dos mais poluentes das indústrias, o RCV com características pozolânicas em sua produção se mostra uma alternativa sustentável, principalmente considerando-se que, de acordo com suas características químicas e o processo de beneficiamento, o RCV pode apresentar uma significativa reatividade tanto com o cimento quanto com a cal (QADIR, 2015; MEDEIROS et al., 2016; CASTRO et al., 2017; SANTOS et al., 2018, MORAIS et al., 2020)

No caso do uso do RCV em concretos, é possível sua aplicação tanto como agrego miúdo ou graúdo como em substituição parcial ao aglomerante. No entanto, alguns testes apontam que, embora o uso do RCV como agregado nos concretos seja viável, é necessário que se tenha atenção à perda de resistência consequente da substituição dos materiais, especialmente nos concretos estruturais (CASTRO et al., 2017; ALVES et al., 2014).

Já nas argamassas, como as solicitações de resistência são menores, o uso do RCV tem um potencial ainda maior. A resistência mecânica nas argamassas trata da capacidade de resistir a solicitações que podem se apresentar na forma de compressão ou tração na flexão (RECENA, 2015), sendo que o valor de $2 \mathrm{MPa}$ de resistência para ambas as propriedades já é considerado usual para argamassas de assentamento ou revestimento (NBR 13281, 2005). Além das resistências mecânicas, a permeabilidade à água também é uma importante propriedade das argamassas, que pode afetar 
diretamente em sua durabilidade. A elevada absorção e evaporação da água pode, nas capilaridades das argamassas, acarretarem em movimentações internas e causar diversas manifestações patológicas como trincas e fissuras. Por estes motivos, e considerando a escassez de diretrizes específicas quanto ao desempenho de argamassas, é fundamental o desenvolvimento de estudos que busquem avaliar suas propriedades.

O beneficiamento do RCV possibilita sua obtenção em granulometrias distintas, o que colabora para que sua aplicação possa ser feita em diferentes fins, tanto na granulometria de aglomerante quanto de agregado. Para a substituição no aglomerante, utilizando o pó de RCV, testes com substituições nos teores de $20 \%$ e $40 \%$ destacaram positivamente nos traços com RCV a melhora na trabalhabilidade e o elevado ganho de resistência aos 28 dias (OLIVEIRA et al., 2019; SAMANDI et al., 2015; SCHACKOW et al., 2015). Quanto à absorção nestas argamassas, observou-se que os teores intermediários, de 20\%, apresentaram melhor desempenho quando comparados ao traço referência, enquanto o traço 40\% apresentou absorção elevada (OLIVEIRA et al., 2019; SCHACKOW et al., 2015). Alguns autores, no entanto, observam que teores de substituição no aglomerante podem causar queda no desempenho, especialmente em relação às propriedades mecânicas como compressão e tração na flexão, sugerindo teores de substituição mais baixos. Além disso, os teores de substituição elevados, por mais que correspondam ao esperado quanto à resistência à compressão apresentam elevadas absorções, fazendo-se necessário o estudo de um traço que equilibre os fatores. O comportamento em argamassas com cal foi bastante semelhante, com destaque para maiores ganhos de resistência à compressão e à tração na flexão (ARAÚJO, 2017).

Já para a granulometria de maior dimensão do resíduo, aplicada na substituição ao agregado, substituições com teores de $5 \%$ e $10 \%$ em argamassas de cimento se mostraram ainda mais eficientes que os traços referências quanto à compressão, tração na flexão, absorção por capilaridade e permeabilidade ao vapor d'água (JIMÉNEZ et al., 2013). Já nos teores acima de $20 \%$ foram identificadas quedas significativas nos valores de resistência e aumento dos teores de absorção (CABRERA et al., 2015). A análise comparativa entre os resultados, no entanto, deve levar em consideração que os resíduos, por serem originados de diferentes argilas, podem apresentar comportamentos distintos, motivo pelo qual se torna fundamental o estudo das propriedades de cada resíduo utilizado provenientes de diferentes jazidas.

Considerando todas as informações colocadas, este trabalho objetiva avaliar a utilização do RCV em argamassas de cimento, testando suas propriedades mecânicas e físicas, além da caracterização do resíduo coletado. A fim de possibilitar uma visão mais ampla, propõem-se avaliar o resíduo em argamassas de cimento em duas tipologias de substituição, sendo uma substituição no aglomerante e outra no agregado.

\section{Metodologia}

A cerâmica utilizada neste trabalho é proveniente do polo de olarias da cidade de Pelotas/RS. A origem da argila e o processo de queima são os fatores que mais interferem nas características da cerâmica (MEDEIROS et al., 2016). Por este motivo, utilizou-se como critério para a coleta do material um resíduo que fosse proveniente de uma olaria que coleta a argila da jazida municipal, cedida pela prefeitura para exploração dos ceramistas, e utilizada por $90 \%$ das empresas da cidade. Quanto ao processo de queima, estipulou-se que o resíduo fosse coletado em uma olaria que trabalhasse com forno de temperatura de queima constante, pois favorece a completa reação química dos elementos da argila, colaborando com a pozolanicidade. Em fornos sem esta automação, a variação da temperatura pode interromper, ou mesmo não causar as reações necessárias para que um material apresente atividade pozolânica. 
O resíduo coletado em natura na olaria apresentou uma considerável discrepância dimensional, e dada sua inaplicabilidade nas argamassas nesta forma, foi necessário um processo de beneficiamento. Optou-se por utilizar o beneficiamento previamente testado em resíduos de cerâmica feito com britador de mandíbulas (OLIVEIRA et al., 2019). O resíduo foi utilizado tanto como agregado miúdo quanto em pó, optando-se por não utilizar outros métodos de moagem combinados, já que aumentaria o consumo energético do beneficiamento e reduziria ainda mais a granulometria do material, dificultando a obtenção das porções média e média grossa de agregado.

Sendo o RCV um material proveniente da argila, é necessário considerar seu potencial para material com atividade pozolânica, de acordo com a NBR 12653 (ABNT, 2014), sendo que os materiais argilosos podem ser classificados como pozolânicos de classe $\mathrm{N}$, uma vez verificados os requisitos estipulados. Essa avaliação foi feita através de espectrometria de energia dispersiva de raio-x (EDX), e analisada de acordo com os requisitos da NBR 12653 (ABNT, 2014), que afirma que para ser considerado pozolânico, um material deve apresentar uma quantidade dos elementos $\mathrm{SiO}_{2}, \mathrm{Al}_{2} \mathrm{O}_{3} \mathrm{e}$ $\mathrm{Fe}_{2} \mathrm{O}_{3}$ tal que a soma das porcentagens ultrapasse $70 \%$ de sua composição. No caso do RCV utilizado neste trabalho, a porcentagem apresentada pelos elementos foram, respectivamente, de $48,22 \%, 24,04 \%$ e $13,15 \%$, resultando na soma de $85,81 \%$, o que indica que, assim como os resíduos avaliados em outros trabalhos (BREHM et al., 2017; CASSOL et al., 2017), o resíduo utilizado aparenta possuir atividade pozolânica.

Para uma análise mais completa da possibilidade reativa do resíduo utilizado foram efetuados também os ensaios de Índice de Atividade Pozolânica (IAP) com cimento, de acordo com a NBR 5752 (ABNT, 2014). O ensaio indicou um índice de atividade pozolânica de $119,57 \%$, que é superior ao mínimo estipulado pela norma de materiais pozolânicos NBR 12653 (ABNT, 2014), que é de 70\%, indicando, portando, que quando em reação com o cimento, o RCV possui atividade pozolânica.

Além do RCV, foram utilizados também como componentes da argamassa a areia média quartzosa lavada, comercialmente disponível na região, e o cimento CPIV-32. A definição do aglomerante utilizado foi feita por ser o mais empregado em argamassas na região deste estudo, além de possuir uma grande quantidade de adições, e por isso, configurar a pior situação de aplicação de resíduo. Como o objetivo deste trabalho é a avaliação das argamassas com RCV, a sua utilização na pior situação de aplicação garante resultados factíveis à realidade de obra.

A areia e o RCV passaram por ensaios de caracterização física a fim de antecipar características do comportamento e averiguar a possibilidade da substituição. Os parâmetros aferidos estão apresentados na Tabela 1. A caracterização possibilitou destacar a alta absortividade do RCV, indicada tanto pela absorção quanto pela massa unitária, demandando uma maior atenção a quantidade de água utilizada nos traços. Por este motivo, e também por utilizar o RCV em estado seco, não se adotou um fator água/cimento para as argamassas, e sim um intervalo de índice de consistência aceitável, que foi de 245 a $265 \mathrm{~mm}$, utilizando-se no traço a quantidade de água que correspondesse a este parâmetro de trabalhabilidade.

Tabela 1: Características físicas do RCV e da areia.

\begin{tabular}{lll}
\hline Parâmetros físicos & RCV & Areia \\
\hline Massa específica $\left(\mathrm{g} / \mathrm{cm}^{3}\right)$ NBR NM 52 (ABNT, 2009) & 2,44 & 2,62 \\
Massa unitária solta $\left(\mathrm{g} / \mathrm{cm}^{3}\right)$ NBR NM 45 (ABNT, 2006) & 0,31 & 1,62 \\
Índice de volume de vazios (\%) NBR NM 45 (ABNT, 2006) & 85,6 & 33,97 \\
Absorção (\%) NBR NM 30 (ABNT, 2001) & 10,26 & 0,66 \\
\hline
\end{tabular}


Os traços escolhidos para este estudo foram nas proporções 1:3 e 1:6 (cimento: agregado), levando em consideração que o traço 1:3 é recomendado para diversas técnicas executivas (YAGIZI, 2013) e também normativamente. No entanto, por ser um traço rico em cimento, a resistência à compressão resultante é muito elevada em comparação com as resistências classificadas pela NBR 7215 (ABNT, 1996). Por este motivo, optou-se por testar também o traço 1:6, que resulta em valores de resistência mecânica mais próximos aos listados na NBR 13281 (ABNT, 2005) para as argamassas.

Para a substituição do aglomerante pelo resíduo foram testados os teores de $5 \%$ e $10 \%$. Estes valores foram definidos considerando conclusões prévias de autores (SILVA et al., 2010) que afirmam que substituições de aglomerante pelo RCV são viáveis apenas em teores até $20 \%$, e que substituições maiores resultam em decréscimos significativos de resistência nas argamassas, enquanto que o teor de $10 \%$ poderia resultar na melhora do desempenho (ARAÚJO, 2017). Já na substituição do agregado pelo resíduo considerou-se que a substituição de $20 \%$ pode levar a uma melhora de desempenho (CARDOSO e FORTI, 2015), mas que teores maiores que este podem afetar negativamente a argamassa. Por este motivo, optou-se por trabalhar com um percentual máximo de $20 \%$, além dos intervalos de $10 \%$ e $15 \%$. A Tabela 2 apresenta todos os traços realizados.

Tabela 2: Traços executados.

\begin{tabular}{lll}
\hline \multirow{2}{*}{$\begin{array}{l}\text { Tipologia de } \\
\text { substituição }\end{array}$} & \multicolumn{2}{l}{ Argamassas de cimento } \\
\cline { 2 - 3 } $\mathbf{1 : 3}$ & $\mathbf{1 : 6}$ \\
\hline Referência & C3_REF & C6_REF \\
5\% no cimento & C3_C5 & C6_C5 \\
10\% no cimento & C3_C10 & C6_C10 \\
10\% na areia & C3_A10 & C6_A10 \\
15\% na areia & C3_A15 & C6_A15 \\
$20 \%$ na areia & C3_A20 & C6_A20 \\
\hline
\end{tabular}

A substituição no aglomerante foi feita sobre a massa do cimento. A substituição no agregado miúdo também foi feita em massa, e considerou uma substituição igualitária do teor definido nas quatro frações de areia. Tanto o resíduo como a areia foram utilizados em estado seco no momento da moldagem. Para a relação água/cimento dos traços considerou-se que, dado o elevado índice de absorção do RCV, o uso do mesmo fator água/cimento em traços com diferentes quantidades de resíduo poderia levar a argamassas com índices de consistência discrepantes. Sendo assim, definiuse por delimitar um índice de consistência para as argamassas entre $245 \mathrm{~mm}$ e $260 \mathrm{~mm}$, variando o consumo de água de acordo com o necessário para atender este parâmetro.

A Tabela 3 indica os parâmetros que foram avaliados neste estudo, além da idade que cada ensaio foi realizado e o número de corpos de prova testados (cps).

Tabela 3: Parâmetros avaliados.

\begin{tabular}{lll}
\hline Parâmetro avaliado & Idade cps no ensaio & Número de cps \\
\hline Resistência à compressão axial (NBR 7215, 1996) & 7,28 e 63 dias & 4 por idade \\
Resistência à tração na flexão axial (NBR 13279, 2005) & 28 dias & 3 \\
Absorção por imersão e índice de vazios (NBR 9778, 2009) & 28 dias & 5 \\
Absorção por capilaridade (NBR 9779, 2013) & 28 dias & 5 \\
\hline
\end{tabular}

A análise estatística aplicada nos resultados foi a análise de variância (ANOVA), que objetiva identificar a diferença significativa entre as médias dos resultados, e se os fatores analisados influenciam de alguma forma nas variáveis dependentes. Além do teste ANOVA, foi realizado também 
um Teste F - distribuição de Fischer, para que seja avaliada a significância estatística da variação de média entre os grupos, sendo considerada a hipótese de nulidade para a análise, de que as médias são todas iguais. A análise de variância foi complementada pela comparação múltipla de médias através do teste de Tukey, que tem como objetivo identificar quais os pares de média são diferentes entre si. Além das variáveis dependentes e independentes, a execução da análise estatística utilizase de outros parâmetros, como o de probabilidade ( $p$-value) e o nível de significância ( $q$. $O p$-value inferior a 0,05 , atribuído de acordo com a distribuição t de Student, define que as relações entre as variáveis definidas possuem uma significância estatística em um nível de confiança de $95 \%$. Já para o nível de significância "đo foi atribuído um valor de $5 \%$, o que significa que os resultados obtidos apresentam um nível de confiança de $95 \%$.

\section{Resultados e discussões}

\subsection{Desempenho mecânico}

$\mathrm{Na}$ Tabela 4 estão apresentadas as médias de resistência à compressão, em MPa, nas idades realizadas. Na Figura 1 são mostrados os valores médios de resistência à compressão aos 7, 28 e 63 dias de idade, dos traços de argamassa 1:3 e 1:6.

Tabela 4: Médias de resistência à compressão em função da idade dos corpos de prova.

\begin{tabular}{llll}
\hline Traço & $\mathbf{7}$ dias & 28 dias & $\mathbf{6 3}$ dias \\
\hline REF 1:3 & 19,56 & 32,15 & 31,81 \\
C5 1:3 & 16,92 & 30,67 & 27,13 \\
C10 1:3 & 13,56 & 26,25 & 30,16 \\
A10 1:3 & 15,44 & 30,26 & 26,83 \\
A15 1:3 & 15,97 & 26,14 & 26,32 \\
A20 1:3 & 14,77 & 26,24 & 27,36 \\
REF 1:6 & 6,29 & 10,76 & 15,43 \\
C5 1:6 & 5,10 & 11,81 & 16,20 \\
C10 1:6 & 6,79 & 10,88 & 9,69 \\
A10 1:6 & 5,79 & 7,41 & 9,42 \\
A15 1:6 & 5,63 & 6,52 & 8,49 \\
A20 1:6 & 5,46 & 6,63 & 9,54 \\
\hline
\end{tabular}


Figura 1: Resultados de resistência à compressão.

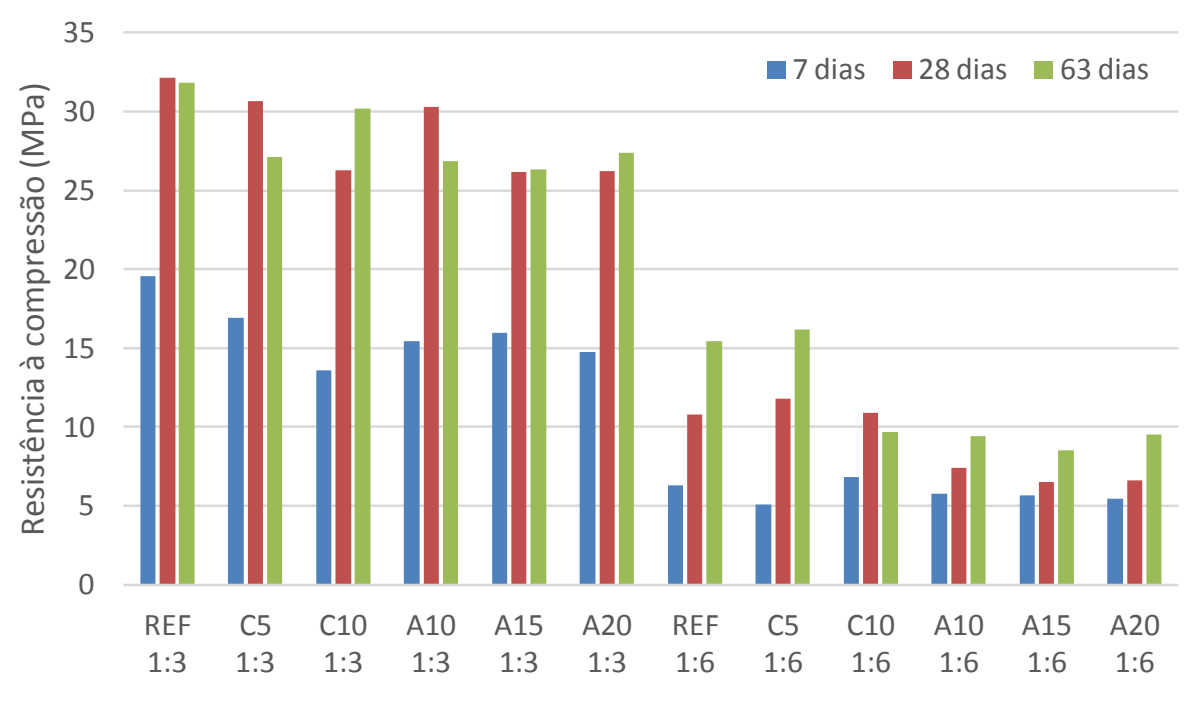

Em todas as idades, o traço REF 1:3 apresentou o maior valor de resistência, enquanto que o comportamento dos traços com substituição oscilou durante o tempo. Aos 7 dias observa-se, por exemplo, que os traços C5 1:3 e C10 1:3 apresentaram decréscimo de resistência em relação ao traço REF 1:3 de maneira proporcional à substituição no aglomerante. Este fato pode estar atrelado à menor porção de cimento na argamassa, uma vez que nos primeiros dias de cura a hidratação do cimento é intensa e representa o fator mais influente nos valores de resistência. Por este motivo o traço C10 1:3, tendo a menor quantidade de cimento de todos os ensaiados, apresentou a menor resistência inicial. Outra evidência desta interferência é o fato de os traços com substituição no agregado não apresentarem relação entre o teor de substituição e a resistência à compressão.

No entanto, ao observar-se os resultados das argamassas de traço 1:6, verifica-se que este comportamento dos traços com substituição no aglomerante não é uma regra das argamassas de cimento com RCV, pois neste grupo não há relação da resistência à compressão com o teor de substituição no aglomerante em nenhuma das idades. Além disso, tanto aos 7 quanto aos 28 dias o traço referência é superado em resistência pelos traços C10 1:6 e C5 1:6, respectivamente. Os traços com substituição no aglomerante, na idade de 28 dias, apresentam queda na resistência mecânica conforme o aumento do teor de substituição apenas aos 28 dias e aos 63 dias, já que aos 7 dias 0 traço 1:6 com 10\% de substituição superou não apenas o traço C5 1:6 mas também o traço referência. Ademais, é importante ressaltar que no caso das argamassas 1:6, essa relação pode ser feita apenas entre os dois traços com substituição no aglomerante, e não com o traço referência, pois o traço com 5\% de substituição desempenhou melhor tantos aos 28 quantos aos 63 dias, de forma que a substituição deste teor de cimento pelo pó de RCV beneficiou o desempenho da argamassa, diferentemente do grupo anterior ou mesmo do teor de $10 \%$.

No entanto, entre as três idades testadas, foi aos 63 dias que os diferentes traços apontaram maiores diferenças. Dentre os comportamentos dos traços nesta idade o que mais se destaca é a redução na resistência à compressão de alguns traços, incomum aos materiais cimentíceos. No grupo das argamassas 1:3 este fenômeno ocorreu nos traços REF 1:3 e C5 1:3. Já no grupo 1:6 o comportamento foi completamente oposto, tendo o traço C5 1:6 a maior resistência do grupo na idade, com ganho em relação aos 28 dias. Em contrapartida, no traço C10 1:6 a resistência decaiu consideravelmente, enquanto que no grupo das argamassas $1: 3$ o traço com $10 \%$ de substituição no cimento foi o único da tipologia de substituição a apresentar ganho de resistência no mesmo intervalo 
de tempo.

Esse fenômeno de decréscimo de resistência em um intervalo de tempo, apesar de inesperado, não é inédito, tendo sido também identificado por Forti e Cardoso (2015) no traço referência 1:3 realizado em seu trabalho, embora não tenha sido discutido. Tendo em vista que a idade de 63 dias é fundamental para identificar a atividade pozolânica do resíduo, é possível que a reação pozolânica de cura tenha sido acelerada inicialmente por intensa hidratação e acabou prejudicada e não realizada completamente. Este resultado difere dos resultados encontrados por Shao et al. (2019) e Oliveira et al. (2019), que obtiveram resultados promissores para a substituição de $10 \%$, em comparação ao traço referência, embora tenham utilizado traços e tipos de cimentos diferentes dos que os utilizados neste trabalho, e por isso os valores de resistência tenham sido maiores. É importante ressaltar que as propriedades das argamassas são especificadas e aferidas com base nos resultados da idade de 28 dias por representar o pico da hidratação do cimento e que, portanto, os resultados atingidos nesta idade são representativos destes traços.

Os dois traços com substituição no aglomerante aos 63 dias, onde esperava-se encontrar características definidas quanto a atividade pozolânica do RCV, apresentaram resultados bastantes distintos. Enquanto o traço C5 apresentou uma considerável queda de resistência, o traço C10 apurou seu desempenho. Dada a reatividade apresentada pelo RCV utilizado neste trabalho é possível afirmar que a quantidade de resíduo utilizada no traço $\mathrm{C} 10$ propiciou a reação pozolânica e causou o ganho de resistência. $O$ fato do traço ter apresentado esta melhora de desempenho apenas aos 63 dias reforça a possibilidade de estar atrelado ao resíduo, pois sabe-se que a reação do RCV é mais lenta que a do cimento, sendo característico que apresentem resistências menores até os 28 dias, mas tenham maior ganho de resistência em idades avançadas (MEDEIROS et al., 2016). Além da atividade pozolânica, a granulometria utilizada do RCV neste traço possibilita que o mesmo aja como fíler no composto cimentíceo, colaborando com o desempenho mecânico. Já no caso do C5, a atividade pozolânica do RCV não acarretou a mesma melhora no desempenho. Uma possibilidade é que a concentração de RCV no composto não seja suficiente para, tanto a reação pozolânica quanto o efeito fíler, serem significativos a ponto de afetar a resistência. Neste caso, a quantidade de RCV utilizada não compensou a porção de cimento retirada do traço.

Tratando das substituições do agregado miúdo pelo RCV, observa-se que em nenhum dos grupos os traços com RCV como agregado miúdo superaram a resistência dos respectivos traços referências. No entanto, no grupo de argamassas 1:6 os traços com substituição no agregado foram mais afetados, apresentando uma maior diferença em comparação com o traço referência. Esta queda de resistência dos traços com substituição no agregado, em relação ao traço referência, pode ter relação com a menor densidade do RCV em relação à areia, sendo que esta possibilidade já foi discutida por Caraseck et al. (2018), que concluíram que a massa unitária dos agregados é um indicativo de sua porosidade, e que, ao usar agregados reciclados, a massa unitária quando muito inferior a massa unitária da areia, pode ser um indicativo de menor resistência à compressão das argamassas, fato este comprovado também neste trabalho, em que a massa unitária do RCV é de $0,31 \mathrm{~g} / \mathrm{cm}^{3}$, enquanto que a da areia é de $1,61 \mathrm{~g} / \mathrm{cm}^{3}$. Além disso, Jíménez et al. (2013) ressaltam que a substituição quando feita em massa pode influenciar negativamente na resistência à compressão.

Nos traços com substituição no agregado também ocorreu queda de resistência à compressão aos 63 dias. No traço A10 1:3 houve um comportamento surpreendente, tendo em vista que o agregado não apresenta grande interferência ao decorrer do tempo na resistência das argamassas.

Através da análise estatística feita pela ANOVA de duas vias sem repetição identificou-se que houve diferença significativa nos dois parâmetros testados, sendo eles os traços e as idades na realização 
dos ensaios de compressão, com p-value de 1,35E-41 e 5,71E-31, respectivamente. Vale ressaltar que na obtenção de $p$-value menor que 0,05 a hipótese de igualdade de médias não se verifica, indicando que os resultados podem ser considerados estatisticamente diferentes. Para a complementação dos resultados, e melhor entendimento dos mesmos, foi realizado o teste de Tukey, com a comparação múltipla das médias, que também demonstrou a diferença significativa entre os parâmetros avaliados. Vale ressaltar que entre os resultados, muitas comparações entre as idades de 28 e 63 dias não se mostraram estatisticamente diferentes.

As argamassas foram testadas também quanto ao seu desempenho de resistência à tração na flexão. Os resultados dos traços de cimento estão apresentados na Figura 2. O comportamento das argamassas foi mais linear entre os traços quanto à tração na flexão do que na avaliação de compressão axial. O traço C5 $1: 3$ se distanciou substancialmente dos demais, com o maior decréscimo de resistência do grupo. Já o traço $\mathrm{C}_{10} 1: 3$ obteve um valor de resistência muito próximo ao apresentado pelo traço referência do grupo, indicando que o teor de substituição do cimento não influencia proporcionalmente na queda de resistência à tração das argamassas $1: 3$, sendo que este maior teor de substituição obteve melhor comportamento em comparação com o traço anterior, C5 1:3. A mesma conclusão é possível ao serem observados os valores apresentados pelos traços com substituição no agregado, embora os valores sejam muito próximos para o grupo de argamassas 1:3. Já no grupo 1:6, o traço com 10\% de substituição no agregado apresentou uma considerável melhora no desempenho.

Figura 2: Resultados de resistência à tração na flexão.

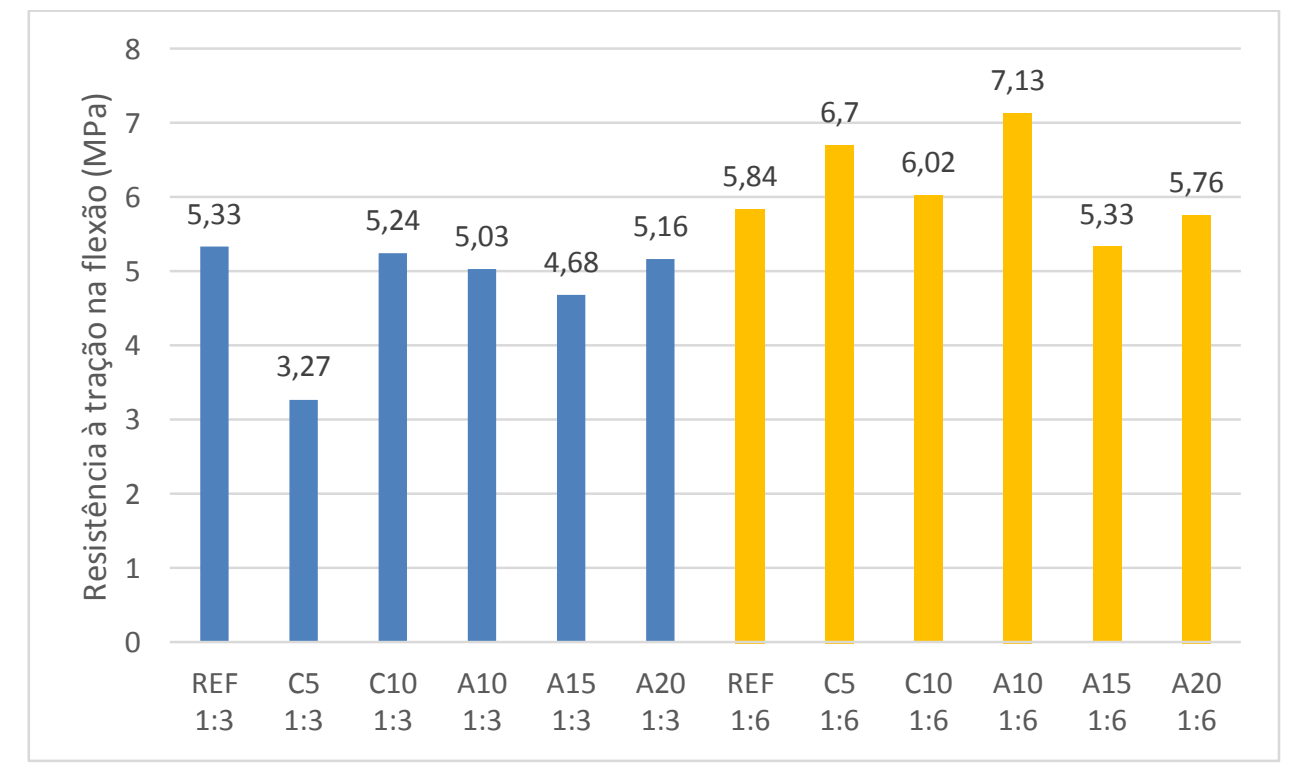

Cabrera et al. (2015), quando testaram diferentes porções do RCV em substituição ao agregado miúdo, reportaram em seu trabalho que não foi possível chegar a alguma conclusão sobre os teores de substituição e a tração na flexão, mas ao avaliarem esta propriedade em diversas idades puderam concluir que com o tempo as substituições nas argamassas de cimento que utilizam RCV podem ganhar resistência à flexão. $O$ trabalho de Dang et al. (2018) também constatou queda de resistência inversamente proporcional a quantidade de resíduo, também com pouca diferença entre valores, o que reafirma a conclusão de que o RCV não causa impacto considerável nas argamassas de cimento.

O traço com $5 \%$ de substituição no aglomerante apenas apresentou decréscimo de resistência à tração na flexão no grupo das argamassas 1:3, tendo uma melhor performance no grupo de 
argamassas 1:6. De fato, no grupo das argamassas 1:3 nenhum dos traços com substituição de RCV ultrapassou o valor de resistência do traço referência, enquanto que nas argamassas 1:6 todos os traços com resíduo superaram o traço referência, com exceção do traço C6_A15. De maneira geral, em ambos os traços é possível afirmar que as substituições do cimento no teor de até $10 \%$ não causam significativa mudança no comportamento das argamassas, fato também observado por Oliveira et al. (2019).

O melhor desempenho, de maneira geral, do grupo de argamassas 1:6 é o comportamento oposto ao esperado, já que, por ser o traço mais rico em cimento, espera-se um melhor desempenho mecânico das argamassas 1:3. Além disso, as argamassas 1:3 apresentaram uma resistência à compressão superior e, de acordo com Recena (2015), a compressão é um parâmetro para a tração. Desta forma, é possível afirmar não apenas que o RCV não interfere na resistência à tração na flexão das argamassas, mas que as argamassas no traço 1:6 desempenham melhor nesse parâmetro, favorecendo sua utilização como revestimento.

Ao realizar-se a análise estatística das 12 famílias de traços, com variável dependente de resposta a resistência à tração na flexão, se chegou a um $p$-value de 0,00739297 , sendo ele menor que 0,05 que indica que a hipótese nula de médias iguais não pode ser considerada. Assim, verificou-se que há pelo menos uma diferença estatisticamente significativa entre os resultados.

Como a análise ANOVA não indica onde a(s) diferença(s) está(ão) aparecendo, foi realizado o teste complementar de Tukey, onde é feita a comparação múltipla entre as médias, tendo como resultado que apenas a comparação entre os traços C5 (para traço 1:3) e A10 (para traço 1:6) apresentou diferença significativa entre as médias. Resultado este coerente, visto a diferença de quantitativo de materiais e também na substituição.

Os agregados naturais e reciclados exercem influências diretas nas argamassas, como foi colocado por Caraseck et al. (2018), sendo a porosidade do material uma das propriedades físicas que exerce interferência no comportamento mecânico das argamassas, pois a maior quantidade de vazios implica em menor resistência à compressão do agregado. O RCV utilizado neste trabalho, ao ser caracterizado quanto suas propriedades físicas, se mostrou um material de elevada porosidade em comparação à areia, por ter apresentado uma massa unitária inferior, e absorção superior, o que é um forte de indicativo de um material com grandes quantidades de vazios internos. Estas características do resíduo implicam no desempenho inferior desta tipologia de substituição.

Cabrera et al. (2015) avaliaram a porosidade das argamassas de RCV em comparação com a argamassa referência, e puderam comprovar que a utilização do RCV como agregado tornou as argamassas mais porosas, tendo aumentado a porosidade proporcionalmente ao aumento do teor de substituição. No entanto, em seu trabalho, também não alterou significativamente o comportamento das argamassas quanto à flexão.

Apesar destas considerações, é necessário observar que o comportamento das argamassas do grupo 1:6 apresentou-se mais homogêneo dentro do grupo considerando as diferentes tipologias de substituição. Já no grupo das argamassas 1:3, os traços C10 e A20, por exemplo, apresentaram comportamentos de desempenho mecânico iguais, apesar de tratarem de diferentes tipologias de substituição. Além disso, as relações demostram que no grupo das argamassas 1:3, a argamassa referência obteve o maior parâmetro de desempenho mecânico, enquanto que no grupo das argamassas 1:6 este fato foi alcançado pelo traço com substituição no aglomerante C5. De fato, tratando-se das substituições no aglomerante, fica visível novamente a melhor ação da reatividade do RCV nas argamassas $1: 6$, visto que os traços se aproximaram - e até superaram - o comportamento 
do traço REF 1:6, enquanto que no grupo das argamassas 1:3 ocorreram grandes decréscimos nos parâmetros mecânicos.

Além das observações quanto ao comportamento do RCV nas argamassas, é necessário relacionar os valores obtidos também com os parâmetros mecânicos para argamassas de assentamento e revestimento classificados na NBR 13281 (ABNT, 2005), que estabelece valores de resistência à compressão axial e de resistência à tração na flexão. Nesta classificação, o valor mínimo estabelecido quanto à compressão axial é de $2,0 \mathrm{MPa}$, enquanto que a maior classificação especifica valores superiores a $8 \mathrm{MPa}$, sendo que para resistência à tração na flexão o valor mínimo é de 1,5 $\mathrm{MPa}$ e o mais alto é de 3,5 MPa. Cabe aqui fazer a ressalva de que esta norma apenas categoriza classes para as argamassas, sem atribuir funções equivalentes a cada uma das classes.

As argamassas de traço 1:3, em todas as suas variações, apresentam valores de resistência muito superiores aos discorridos pela norma, representando uma problemática do ponto de vista de um uso racional dos recursos na construção, sendo, portanto, superdimensionada para aplicações como revestimento. Já se tratando de outras aplicações, tais como assentamento, chumbamento entre outras, as elevadas resistências podem ser benéficas ao sistema, de forma que ainda se justifica a aplicação no RCV nas argamassas dessa proporção. Já para as argamassas de cimento do traço 1:6, os valores de desempenho mecânico aferidos foram mais próximos às situações de argamassas de revestimento descritas da norma, indicando a potencialidade da sua aplicação neste contexto, não descartando, também, as demais aplicações como assentamento, principalmente considerando os satisfatórios comportamentos frente à compressão de alguns traços com RCV, como C5 1:6 e C10 $1: 6$.

\subsection{Desempenho físico}

$\mathrm{Na}$ Figura 3 estão apresentados os resultados obtidos quanto à absorção por capilaridade para os traços de argamassa, aos 28 dias. A primeira análise indica que os traços com base 1:3, com substituição no agregado, tendem a apresentar maior absorção por capilaridade conforme aumenta a quantidade de RCV no traço. O que não aconteceu entre os mesmos traços com base 1:6, onde o $15 \%$ de substituição foi que apresentou menor taxa de absorção. Já entre os traços com substituição no aglomerante, apenas o traço C5 (1:3) obteve um menor índice de absorção que o traço referência, o que também ocorre no C5 (1:6). Importante observação é que todos os traços do 1:6 absorveram menos que o referência (REF 1:6), o que não notou-se no 1:3. 
Figura 3: Resultados de absorção por capilaridade.

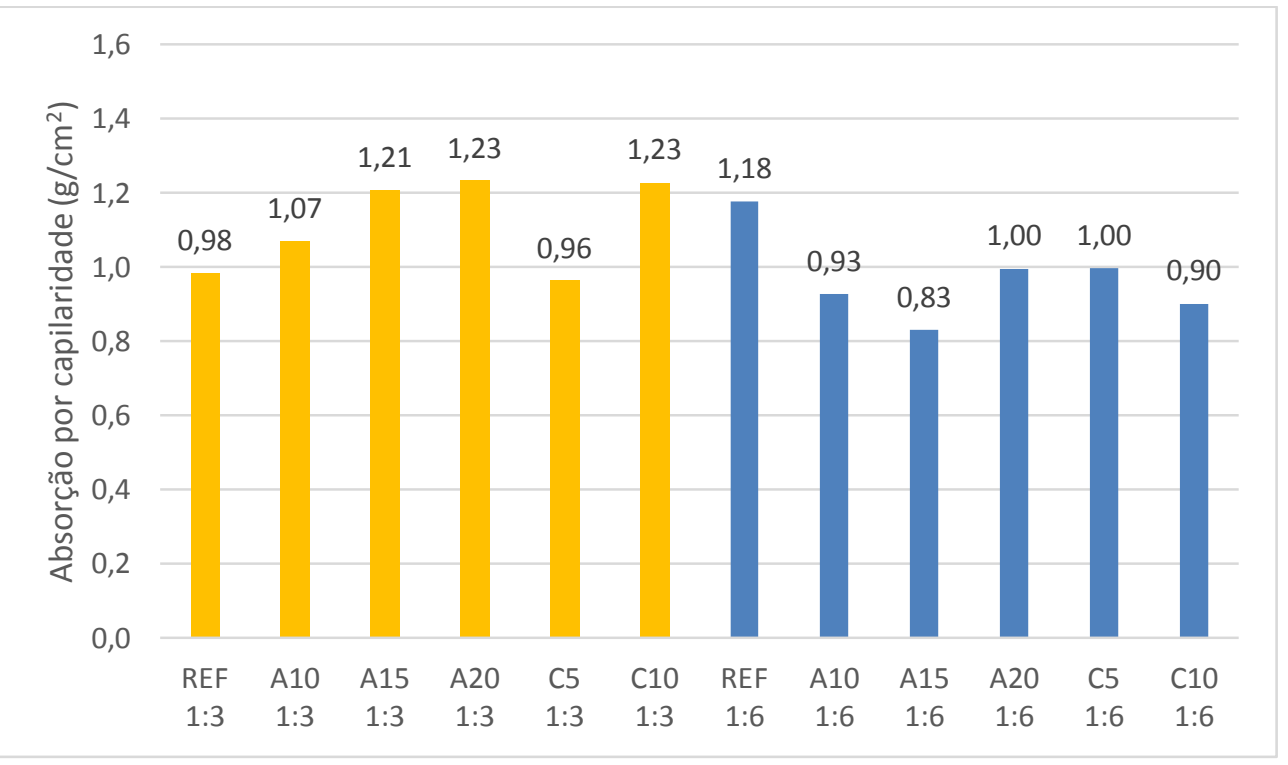

Ao avaliarem a absorção por capilaridade das argamassas de cimento, Jiménez et al. (2013) obtiveram melhoria de desempenho, estatisticamente comprovada, ao aplicar o RCV como agregado miúdo, especialmente nos teores de $5 \%$ e $10 \%$ de substituição. Os autores atribuíram a menor absorção ao fato do formato dos grãos de RCV possibilitar menor quantidade de poros internos nas argamassas. Os resultados do presente trabalho se assimilaram mais com os resultados de Cardoso e Forti (2015), que também obtiveram maior absorção por capilaridade ao substituir $10 \%$ da areia por RCV. Estas diferenças podem ser provenientes da característica física dos resíduos, ou mesmo de diferenças no processo de moldagem dos corpos de prova. Vale destacar que esta análise é feita considerando apenas as conclusões de interferência do RCV nas argamassas, uma vez que os valores são incomparáveis, pelos trabalhos utilizarem traços diferentes.

A interferência do pó de RCV presente nas substituições do aglomerante no comportamento das argamassas, quanto à absorção por capilaridade, foi distinto entre 1:3 e 1:6. Os resultados (C5 1:3; C5 1:6 e C10 1:6) conferem com os resultados obtidos por Schackow et al. (2015), onde todos os traços com substituição no aglomerante apresentaram absorção por capilaridade inferior ao traço referência, tendo o RCV como aglomerante tornado as argamassas menos porosas.

Ao ser realizada a análise estatística, tendo como variável dependente de resposta a absorção por capilaridade, chegou-se a um p-value de 5,92987E-05, que mostra que houve pelo menos uma diferença estatisticamente significativa entre médias. Ao realizar-se o teste de múltiplas comparações de médias de Tukey, os traços com substituição parcial do cimento foram diferentes quando comparados aos traços de referência. Já na substituição do agregado não houve semelhança entre os traços e o traço referência.

A Figura 4 apresenta os resultados obtidos para as argamassas de cimento quanto à absorção por imersão. As substituições no agregado indicam um aumento de absorção conforme aumentou o teor de substituição. No entanto, neste parâmetro, as substituições no aglomerante também apresentaram certa constância no que diz respeito à relação absorção $x$ teor de substituição, embora tenham resultados em valores menores que os da substituição no agregado.

Na Figura 5 estão representados os valores de índice de vazios para os mesmos traços. Observa-se que as quantidades de vazios das argamassas acompanharam os valores de absorção. As 
referências carecem de análises sobre a absorção por imersão. No entanto, Vieira (2005) em seu trabalho apresentou resultados para argamassas com substituição do aglomerantes pelo RCV nos teores de $20 \%$ e $40 \%$, onde os índices de vazios reduziram em relação ao traço referência.

Figura 4: Resultados de absorção por imersão.

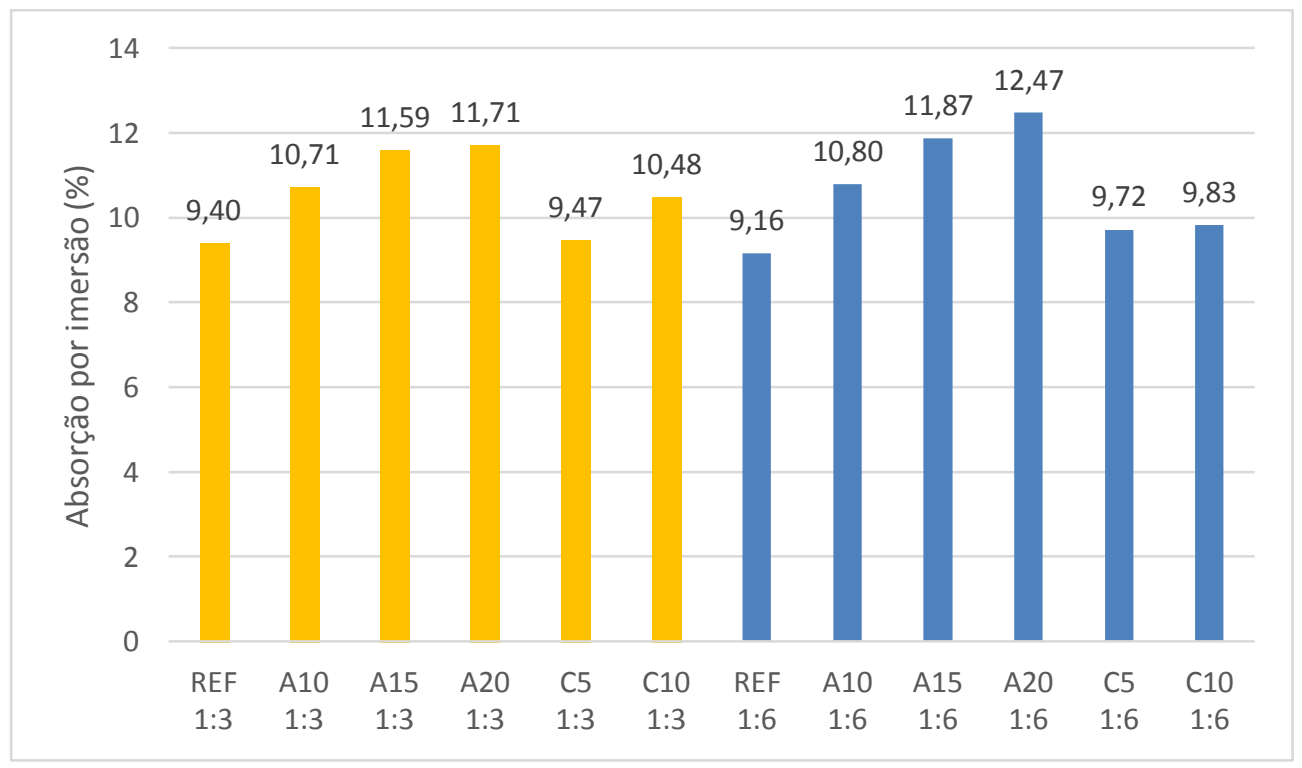

Figura 5: Resultados de Índice de Vazios.

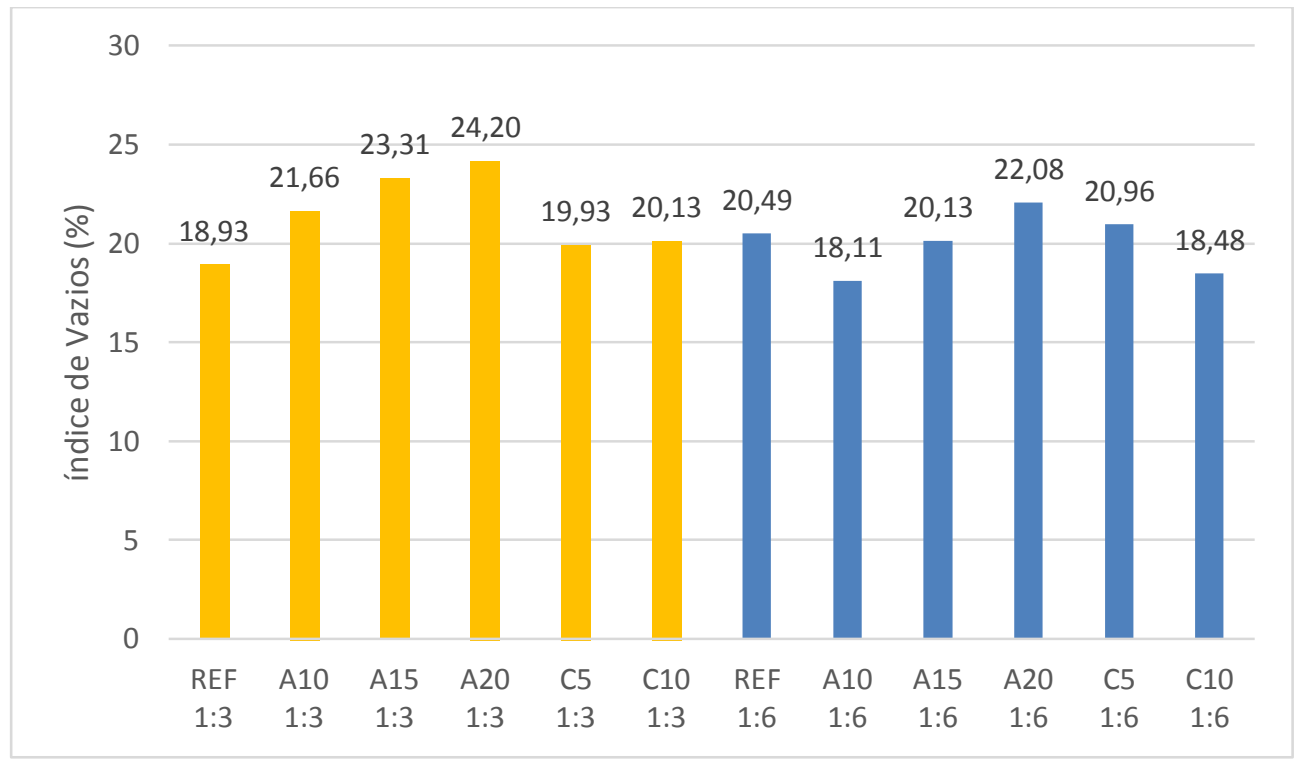

Ao realizar-se a análise estatística ANOVA das 12 famílias de traços, sendo a variável de resposta a absorção por imersão, chegou-se ao valor de 1,22321E-12 para o $p$-value, que indica diferença significativa entre os resultados das médias. Restando, agora, determinar onde foram observadas as diferenças. Para isso foram obtidos os resultados por Tukey, ressaltando-se que a comparação entre a referência 1:6 e os dois traços de substituição do cimento por RCV não apresentaram diferença significativa, sendo que o mesmo ocorreu na família de traços 1:3. Tal fato mostra que a substituição do aglomerante por RCV não alterou estatisticamente os resultados de absorção por imersão. Já as substituições dos agregados foram todos diferentes estatisticamente. Um resultado que vale ser ressaltado é que entre os traços referências 1:3 e 1:6 não houve diferença, portanto os dois traços se 
comportam de maneira igual mesmo com a grande diferença no quantitativo de agregado.

Para a variável dependente de resposta índice de vazios chegou-se a um p-value de 8,39352E-11, e sendo ele menor que 0,05 , demonstra que houve diferença significativa entre as médias. Porém, como ocorreu na análise dos dados de absorção por imersão, pelo teste de Tukey os traços que substituíram cimento não apresentaram diferença quando comparados com as referências. Também, houve diferença nos valores médios quando das substituições no agregado. Novamente, os traços referências 1:3 e 1:6 não foram diferentes estatisticamente.

Sendo assim, é possível afirmar que a presença do RCV nas argamassas interferiu em seus comportamentos no que diz respeito à absorção por imersão, mas apenas nos traços que foram substituídos os agregados. Sendo, possível, indicar substituições do cimento por RCV em função de não terem aumentado a absorção por imersão.

\section{Conclusões}

A cidade de Pelotas é reconhecida com um grande polo produtor de materiais cerâmicos da região Sul do estado do Rio Grande do Sul, sendo que 90\% das empresas da cidade utilizam a argila da jazida municipal, cedida para exploração dos ceramistas. Segundo Medeiros et al. (2016), a origem da argila, que pode apresentar diferentes características de uma região para outra região, e o processo de queima são os fatores que mais interferem nas propriedades do material acabado. Desta maneira, este trabalho é uma grande contribuição no sentido do avanço do conhecimento da utilização de materiais recicláveis incorporados às argamassas utilizadas na construção civil. Esta importância se dá no sentido do conhecimento das características de um material bastante importante na economia local, e que pode ser reutilizado de uma forma diferente na cadeia produtiva, sendo minimizada a possibilidade de descartes inadequados e conferindo diferentes propriedades às argamassas. Mostrada a importância deste estudo, algumas conclusões estabelecidas podem ser expressas conforme segue.

A análise de diferentes traços com utilização do RCV permite concluir que a ação do resíduo pode ocorrer de desiguais formas em argamassas de diferentes proporções, mesmo que os materiais utilizados sejam os mesmos, reforçando a importância de diversos estudos e análises quando se trata da reciclagem de resíduos em materiais construtivos. No caso das argamassas de cimento e areia, percebeu-se um aspecto bastante importante quando da comparação do comportamento mecânico em termos de resistência à tração na flexão, onde as argamassas com menor consumo de cimento (traço 1:6) apresentaram melhor desempenho quando em comparação com o traço 1:3, sendo o traço de maior resistência entre todos uma argamassa com RCV (A10 1:6), superando inclusive as argamassas de referência. Esse comportamento não foi o mesmo ao serem analisados os resultados de resistência à compressão, onde os traços com maior consumo de cimento apresentaram os melhores desempenhos. Além disso, as argamassas de referência foram as que mais resistiram às cargas de compressão, quando comparadas às argamassas que continham o RCV. Também, as argamassas com substituição no agregado foram as que apresentaram piores resultados, fato este, associado à menor densidade do RCV quando comparado à areia, que acabou por conferir menor resistência a essas argamassas. Entretanto, sabe-se que este parâmetro mecânico não é o mais importante quando o assunto é argamassa, sendo as mesmas mais solicitadas por tensões de tração. Portanto, pode-se sugerir, visto por este aspecto, o uso de argamassas com substituições de materiais por RCV, tendo as mesmas um bom desempenho mecânico.

Em termos do comportamento físico das argamassas, analisando-se a absorção por capilaridade, novamente as argamassas com menor consumo de cimento (traço 1:6) apresentaram melhores 
desempenhos quando comparadas às argamassas de traço 1:3. Também, os traços com substituição parcial do cimento ou da areia por RCV tiveram comportamentos bastante similares, com absorções inferiores à referência, indicando um ponto positivo das mesmas. Entretanto, ao analisar-se agora a absorção por imersão, pode-se notar um comportamento diferente da absorção por capilaridade, onde tanto os traços 1:3 quanto 1:6 tiveram desempenhos bastante parecidos, com as argamassas que continham substituição parcial da areia por RCV apresentando absorções superiores às argamassas de referência. Por outro lado, as substituições do cimento por RCV beneficiou as argamassas, com absorções inferiores às substituições parciais do agregado, e com valores bastante próximos das argamassas de referência. Esse também foi o comportamento observado no ensaio de índice de vazios, mostrando a correlação direta da absorção por imersão com o índice de vazios das argamassas.

Desta forma, conclui-se que a aplicação do RCV é uma realidade para diversas situações de tipologia das argamassas, de substituição e também de traço, apresentando uma vasta quantidade de possibilidades quanto à reciclagem deste resíduo da indústria da construção civil, colaborando com o seu descarte e com a redução de materiais construtivos como o cimento e a areia quem representam impactos ambientais.

\section{Agradecimentos}

À Capes pelo fomento a esta pesquisa.

\section{Referências}

AGÊNCIA BRASILEIRA DE DESENVOLVIMENTO INDUSTRIAL - ABDI. Estudo Técnico Setorial da Cerâmica Vermelha: Subsídios para a elaboração do plano de desenvolvimento Sustentável da cadeia produtivo de cerâmica vermelha. Brasília: Invetta, 2016. 265p.

ALVES, A. V.; VIEIRA, T. F.; BRITO, J. de.; CORREIA, J. R., Mechanical propeties of structural concrete with fine recycled aggregates. Construction and Buildiing Materials, vol. 64, p. 103-113, ago. 2014.

ARAÚJO, A. R.; Influencia da utilização do resíduo de cerâmica vermelha nas propriedades de argamassas mistas. Dissertação do Programa de Pós-Graduação em Engenharia de Civil, Universidade Federal de Rio Grande do Norte, Natal 2017.

ASSOCIAÇÃO BRASILEIRA DE NORMAS TÉCNICAS, Materiais pozolânicos - Determinação da atividade pozolânica com cimento Portland aos 28 dias. NBR 5752. Rio de Janeiro, 2014. 4p.

ASSOCIAÇÃO BRASILEIRA DE NORMAS TÉCNICAS. Argamassa para assentamento e revestimento de paredes e tetos - Requisitos. NBR 13281. Rio de Janeiro, 2005. 3 p.

ASSOCIAÇÃO BRASILEIRA DE NORMAS TÉCNICAS. Cimento Portland - Determinação da resistência à compressão. NBR 7215. Rio de Janeiro, 1996.

ASSOCIAÇÃO BRASILEIRA DE NORMAS TÉCNICAS. Execução de revestimentos de paredes e tetos de argamassas inorgânicas. NBR 7200. Rio de Janeiro, 1992.

ASSOCIAÇÃO BRASILEIRA DE NORMAS TÉCNICAS. Materiais pozolânicos - Requisitos. NBR 12653. Rio de Janeiro, 2014. $10 \mathrm{p}$.

ASSOCIAÇÃO BRASILEIRA DE NORMAS TÉCNICAS. Argamassa e concreto endurecidos Determinação da absorção de água por capilaridade. NBR 9779. Rio de Janeiro, 2013. 3 p. 
ASSOCIAÇÃO BRASILEIRA DE NORMAS TÉCNICAS. Argamassa e concreto endurecidos Determinação da absorção de água, índice de vazios e massa específica. NBR 9778. Rio de Janeiro, 2009. 4 p.

ASSOCIAÇÃO BRASILEIRA DE NORMAS TÉCNICAS. Argamassa para assentamento e revestimento de paredes e tetos - Determinação da resistência à tração na flexão e à compressão. NBR 13279. Rio de Janeiro, 2005. 9 p.

ASSOCIAÇÃO NACIONAL DA INDÚSTRIA CERÂMICA - ANICER. Dados Oficiais, 2014. Disponível em: http://anicer.com.br/setor/dados-oficiais/. Acesso em: 05/04/18

BREHM, F. A. ; KULAKOWSKI, M. P. ; BROCKER, D. M. ; HANSEN, D. M. . Avaliação da atividade pozolânica do resíduo de cerâmica vermelha comparado com metacaulim. In: 5o Encontro Nacional Sobre Aproveitamento de Resíduos na Construção Civil - ENARC 2017, 2017, Fortaleza/CE. Anais 2017 - ENARC - ENCONTRO NACIONAL SOBRE APROVEITAMENTO DE RESÍDUOS NA CONSTRUÇÃO, 2017.

CABRERA, F. G. C.; SOBERÓN, J. M. G.; SÁNCHEZ, J. L. A.; REA, S. P. A.; HIGUERA, R. C., Mechanical properties of mortar containig recycled ceramic as fine aggregate replacement. Revista de la Construcción, vol. 14, n. 3, p. 22-29, dez. 2015.

CARASECK, H.; GIRARDI, A. C. C.; ARAÚJO, R. C.; ANGELIM, R.; CASCUDO, O., Estudo e avaliação de agregados reciclados de resíduo de construção e demolição para argamassas de assentamento e revestimento. Revista Cerâmica, vol. 64, n. 370, São Paulo, abr/mai, 2018.

CARDOSO, J. T. O.; FORTI, N. C. S., Estudo para aplicação de resíduos de cerâmica vermelha na produção de argamassas cimentíceas. Anais do $\mathrm{V}$ Encontro de Iniciação em Desenvolvimento Tecnológico e Inovação. Set. 2015.

CASSOL, G.; SEGANTINI, A. A. S. Avaliação do Resíduo de Cerâmica Vermelha como material pozolânico em matrizes cimentantes. In: $59^{\circ}$ Congresso Brasileiro do Concreto, 2017, Bento Gonçalves. 59 Congresso Brasileiro do Concreto, 2017.

CASTRO, A. L.; SANTOS, R. F. C.; GONÇALVES, K. M.; QUAIONI, V. A., Caracterização de cimento compostos com resíduo da indústria da cerâmica vermelha. Revista Cerâmica, vol. 63, n.365, São Paulo, São Paulo, jan./mar., 2017

DANG, J.; ZHAO, J.; HU, W.; DU, Z.; GAO, D., Properties of mortar with waste clay brick as fine aggregate, Construction and Building Materials, vol. 166, p. 898-907, mar. 2018

JIMÉNEZ, J. R.; AYUSO, J.; LÓPEZ, M.; FERNÁNDEZ, J. M.; BRITO, J., Use os fine recycled aggregates from ceramic waste in masonry mortar manufacturing. Construction and Building Materials, vol. 40, p. 679-690, 2013.

MEDEIROS, M. H. F.; SOUZA, D. J.; FILHO, J. H.; ADORNO, C. S.; QUARCIONI, V. A.; PEREIRA, E., Resíduo de cerâmica vermelha e fíler calcário em compósito de cimento Portland: efeito no ataque por sulfatos e na reação álcali-sílica. Revista Matéria, vol.21, n. 02, p. 282-200, 2016

MORAIS, M. H. L; SOUZA, W. M; RIBEIRO, A. J. A. Use of red ceramic waste as fine aggregate in concretes. Research, Society and Development, 9(7): 1-17, 2020.

OliVeIRA, E. M.; OliVEIRA, C. M.; PETERESON, M.; PELISSER, F.; OliVEIRA, C. M. de; ANTUNES, E. G. P., Análise da resistência à compressão e tração de argamassa com adição de resíduo de cerâmica vermelha. Revista Matéria, vol. 24, n. 2, Rio de Janeiro, 2019. 
QADIR, S. S.; Strength and behavior of self compacting concrete with crushed ceramic tiles as partial replacement for coarse aggregate to elevated temperature. International Journal of Engeneering Technology, Management and Applied Science, vol. 3, n. 04, p. 278-286, abr. 2015.

RECENA, Fernando Antonio Piazza. Conhecendo argamassa. $2^{\circ}$ ed. Porto Alegre: EDIPURS, 2015. $188 p$.

SAMANDI, M.; HUSSIN, M. W.; LEE, H. S.; SAM, A. R. M.; ISMAIL, M. A.; LIM, N. H. A. S.; ARIFFIN, N. F.; KHALID, N. H. A., Properties of mortar containing ceramic powder waste as cement replacment. Jurnal Teknologi, vol. 77, n.12, p. 93-97, dez. 2015.

SANTOS, R.F.C; CASTRO, A. L; GONÇALVES, K. M. Produção de concreto autoadensável incorporado com resíduo da indústria de cerâmica vermelha. Matéria (Rio J.) 23 (3), 1-15, 2018.

SCHACKOW, A; STRINGARI, D.; SENFF, L.; CORREIA, S. L.; SEGADÃES, A. M., Influence of fired clay brick waste additions on the durability of mortars. Cement and Concrete Composites, vol. 62, p. 82-89, set., 2015.

SHAO, J.; GAO, J.; ZHAO, Y.; CHAO, X., Study on the pozzolanic reaction of clay brick powder in blended cement pastes, Construction and Building Materials, vol. 213, p. 209-215, 2019.

SILVA, J.; BRITO, J. de; VEIGA, R., Recycled red-clay ceramic construction and demolition waste for mortar productions. Journal of Materials in Civil Engeneering, vol. 22, n. 3, p. 236-244, 2010.

VIEIRA. A. A. P.; Estudo do aproveitamento de resíduos de cerâmica vermelha como substituição pozolânica em argamassas e concretos. Dissetação, Programa de Pós-Graduação em Engenharia Urbana, Universidade Federal da Paraíba, João Pessoa, 2005.

YAGIZI, W. A técnica de edificar, 13 edição, São Paulo, Editora Pini, Sinduscon, 2013.

\section{Francielli Priebbernow Pinz}

Graduação em Arquitetura e Urbanismo (2017) e Mestrado em Arquitetura e Urbanismo (2019) pela Universidade Federal de Pelotas. Atuou como professor substituto em Instituto Federa Sul-RioGrandense (2017-2019) e atualmente atua como Arquiteta em Otimiza Arquitetura. Tem experiencia na área de Arquitetura e Urbanismo, atuando nos seguintes temas: RCV, argamassas, Reciclagem de resíduos, Tecnologia da Arquitetura.

Contribuição de coautoria: fundamentação teórico-conceitual e problematização; pesquisa de dados; elaboração de figuras e tabelas; Fotos; elaboração e redação do texto; seleção das referências bibliográficas

\section{Charlei Marcelo Paliga}

Possui graduação em Engenharia Civil pela Universidade Federal do Rio Grande (2000), mestrado em Engenharia Oceânica pela Universidade Federal do Rio Grande (2003) e doutorado em Engenharia Civil pela Universidade Federal do Rio Grande do Sul (2007). Atualmente é professor associado 3 da Universidade Federal de Pelotas. Tem experiência na área de Engenharia Civil, atuando principalmente nos seguintes temas: projeto de estruturas de concreto armado, método dos elementos finitos, recuperação/reforço de estruturas de concreto com polímeros reforçados com fibras, confiabilidade estrutural.

Contribuição de coautoria: elaboração e redação do texto, fundamentação teórico-conceitual e 
problematização; revisão do texto.

\section{Ariela Da Silva Torres}

Graduação em Engenharia Civil pela Universidade Católica de Pelotas (2003), Mestrado em Engenharia Civil com ênfase em estrutura - PPGEC/UFRGS (2006) e Doutorado em Engenharia Civil com ênfase em estruturas - PPGEC/UFRGS (2011). Professora Associada 1 na Faculdade de Arquitetura e Urbanismo da UFPel. Atua no PPG em Arquitetura e Urbanismo (professora permanente) na linha de pesquisa: Tecnologia e Conservação do Ambiente Construído. Líder do Grupo de pesquisa Esudos de Patologias e materiais (NEPAMAT). Tem experiência na área de Engenharia Civil, atuando principalmente nos seguintes temas: projeto de estruturas de concreto armado, Patologia das Construções, uso de resíduos na construção civil.

Contribuição de coautoria: elaboração de figuras e tabelas; Fotos; elaboração e redação do texto, fundamentação teórico-conceitual e problematização; pesquisa de dados e análise estatística; revisão do texto.

Como citar: PINZ, Francielli Priebbernow, PALIGA, Charlei Marcelo, TORRES, Ariela Da Silva. Avaliação do desempenho mecânico e físico de argamassas com resíduo de cerâmica vermelha. Revista Paranoá. n.31. Jul/dez de 2021. DOI: http://doi.org/10.18830/issn.1679-0944.n31.2021.05

Editor responsável: Daniel Sant’Anna 